\title{
Combustion Characteristics of Horizontal Diesel Spray Burner in Low-Pressure Chamber Based on Multivariate Correlation Analysis
}

\author{
Kai Xie $\mathbb{D}^{1},{ }^{1}$ Yunjing Cui $\mathbb{D}^{2}{ }^{2}$ Xingqi Qiu, ${ }^{1}$ and Jianxin Wang ${ }^{3}$ \\ ${ }^{1}$ College of Chemical Engineering, China University of Petroleum (East China), Qingdao 266580, China \\ ${ }^{2}$ College of Electromechanical Engineering, China University of Petroleum (East China), Qingdao 266580, China \\ ${ }^{3}$ Research and Development Department, Yunnan Aerospace Industry Co. LTD, Kunming 650217, China \\ Correspondence should be addressed to Kai Xie; xiekai199101@163.com and Yunjing Cui; cuiyj@upc.edu.cn
}

Received 2 March 2019; Accepted 17 August 2019; Published 27 November 2019

Academic Editor: Mohammad Hassan Khooban

Copyright $\odot 2019$ Kai Xie et al. This is an open access article distributed under the Creative Commons Attribution License, which permits unrestricted use, distribution, and reproduction in any medium, provided the original work is properly cited.

At present, the burning problem of low power burners widely used in emergency and stove heating on the plateau has gradually attracted people's attention. The fuel injection pressure, inlet air flow, air distribution regulation coefficient, and environmental pressure were considered respectively, and then the four factors and six levels of a uniform experimental investigation were conducted in a low-pressure chamber with adjustable atmospheric pressure. The flame morphology, flame temperature, and NO emission were investigated, and their correlation with each independent variable was analyzed. In addition, burning of droplet swarm was obtained with the simulate numerical calculation by the ANSYS FLUENT. The results showed that the low-pressure environment had a negative correlation with the maximum width and position of flame, the characteristics of flame uplifted and NO emission. Air volume determines the length of the flame, and atmospheric pressure and fuel injection pressure determine the maximum width of the flame. The shape of the horizontal jet flame in plateau environment is more dependent on the regulation of air volume. In order to reduce NO emission in plateau environment, it may be necessary to maintain a large air supply volume and reduce fuel injection pressure appropriately. At the microscopic level of droplet combustion, change mechanisms of macro flame shape in different subatmosphere were analyzed. The mechanism of flame morphological change in the plateau environment is the increase in droplet burning time and path. The adjustment of flame under sub-atmospheric pressure through the change of operating parameters is essential to improve the burning rate of droplets.

\section{Introduction}

Low power fuel burners are widely used in various chemical heating and heat transfer equipment $[1,2]$. At present, there are always some problems such as insufficient combustion, high pollutant emission and low efficiency in the application of the plateau environment. Especially in China, there is the Tibet plateau, the largest plateau in the world. As we all know, the main change in the plateau environment is the decrease in atmospheric pressure [3]. With the decrease in atmospheric pressure, oxygen content decreases accordingly [4], which will lead to the change of chemical reaction mechanism of fuel combustion in such low-pressure and low-oxygen environment, and eventually lead to the change of flame morphology [5], flame temperature [6], and pollutant emission
[7]. The influence of the operating parameters of the burner and the atmospheric pressure changes in the plateau environment on the combustion characteristics of the small diesel burner is complex, especially for different atmospheric pressures at different altitudes.

For a long time, scholars have been deeply studying the vertical jet flame of gaseous fuel under low atmospheric pressure [8-12]. For liquid fuel combustion behavior at reduced atmospheric pressure, the influence of atmospheric pressure on the diffusion characteristics of pool fire was first investigated [13]. It was found that when the atmospheric pressure was lower than $0.08 \mathrm{MPa}$, the highest value of flame temperature was far away from the burner outlet with the decrease in pressure. The standard combustion experiment of liquid fuel was completed through the small size mobile 


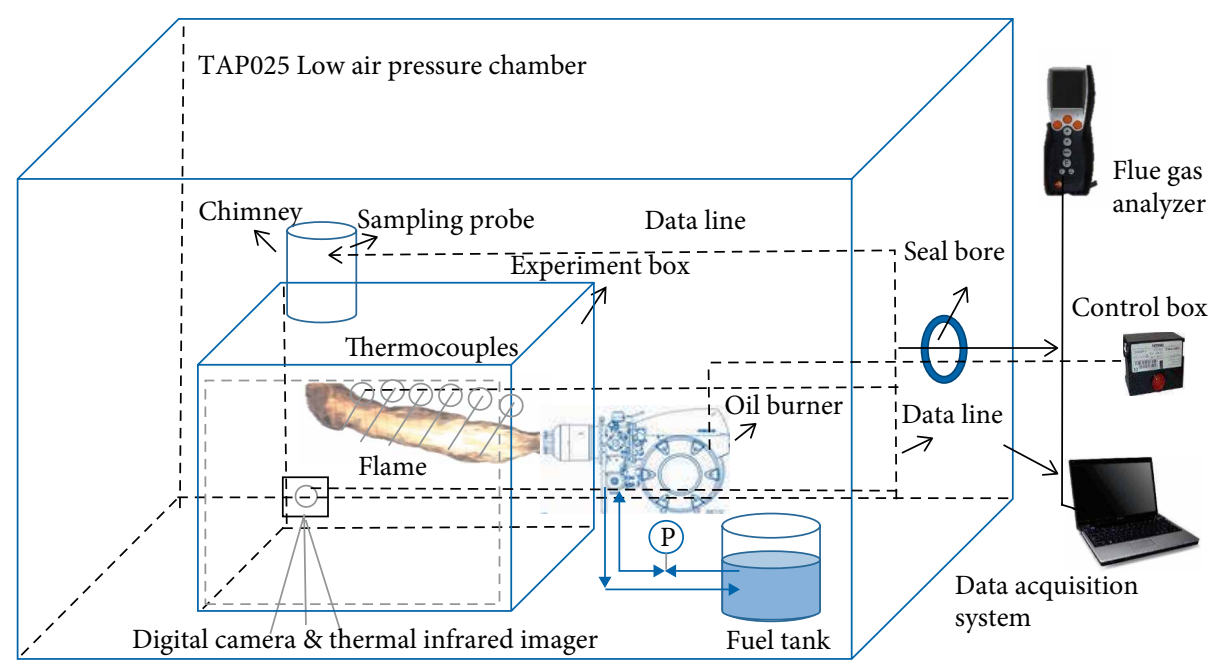

FIGURE 1: Schematic diagram of the experimental device.

laboratory carried by helicopter [14]. The combustion chamber size was $6 \mathrm{~m}(\mathrm{~L}) \times 2.8 \mathrm{~m}(\mathrm{~W}) \times 2.1 \mathrm{~m}(\mathrm{H}) \mathrm{m}$, and the altitude was within the range of $400 \mathrm{~m}(97 \mathrm{kPa})$ to $3000 \mathrm{~m}$ $(71 \mathrm{kPa})$. Experimental results show that the combustion rate decreases with the decrease in ambient pressure. Scholars conducted a similar oil pan fire comparative combustion experiment at higher altitudes $[15,16]$, and the experimental results verified that the flame height of liquid fuel increased with the increase in altitudes. For flame temperature, most scholars believe that low-pressure conditions will cause the temperature rise in some flame areas [17-19], which will also lead to an increase in pollutants to a certain extent. Some scholars also found that the flame temperature of $n$-heptane at the height of 4250 meters was slightly higher than that at the lower altitude [20]. For the fuel burner, its operating parameters mainly include fuel injection pressure [21], air volume [22], air distribution condition coefficient [23], etc., which have an important impact on the combustion characteristics of the flame. However, the influence of these operating parameters on the combustion characteristics of a flame in a lowpressure environment has been rarely reported. In addition, in the low-pressure environment, pollutant emissions also need to be focused. In low-pressure environments, the reduction of oxygen content due to atmospheric pressure may eventually lead to substandard pollutant discharge [24].

In this paper, various operating parameters and atmospheric pressure have been studied experimentally. The flame morphology was analyzed by image processing method and the pollutant emission was sampled by a smoke analyzer. The temperature distribution on the flame trajectories was measured by the thermocouples and a thermal imager. The primary and secondary effects of operating parameters on the combustion in the plateau environment were obtained. The combustion mechanism of spray flame in plateau environment is explained from the perspective of droplet combustion. It is of great significance to the control of burner flame and temperature in a high altitude environment.

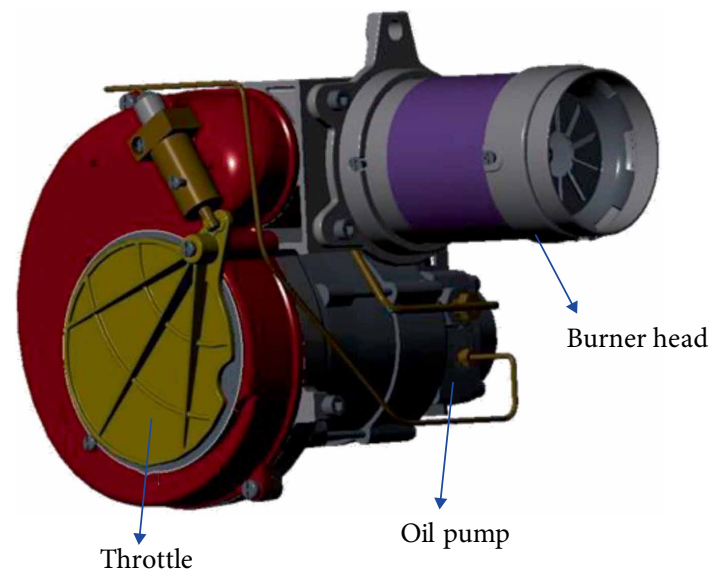

Figure 2: The three-dimensional model diagram of the main components of the Riello 40-G5 oil burner.

\section{Experimental Setup and Method}

2.1. Experimental Device. The low-pressure chamber has become the main means to simulate different sub-atmospheric pressure environment $[25,26]$. The combustion experiments in this paper were all carried out in a low-pressure chamber. The comparison with the local atmospheric pressure (Kunming, China, $0.08 \mathrm{MPa}$ ) shows that the low-pressure chamber is feasible. The schematic diagram of the overall experimental device is shown in Figure 1.

In the experiment, the Riello 40-G5 type burner is fixed to an experimental box and placed in a low-pressure chamber $(3 \mathrm{~m}$ (length) $\times 2.5 \mathrm{~m}$ (height $) \times 3 \mathrm{~m}($ width $))$. Figure 2 shows the main three-dimensional configuration of this fuel oil burner. The adjustable pressure range of this low-pressure chamber is $0.045-0.10 \mathrm{MPa}$. Images are widely used for the observation of flame morphology [27]. A high-definition camera was used to record the flame in the low-pressure chamber no. 0 diesel is used for combustion. In order to monitor pollutant emission, the probe of the flue gas analyzer is inserted at the flue gas outlet, and the data are transmitted to the data 


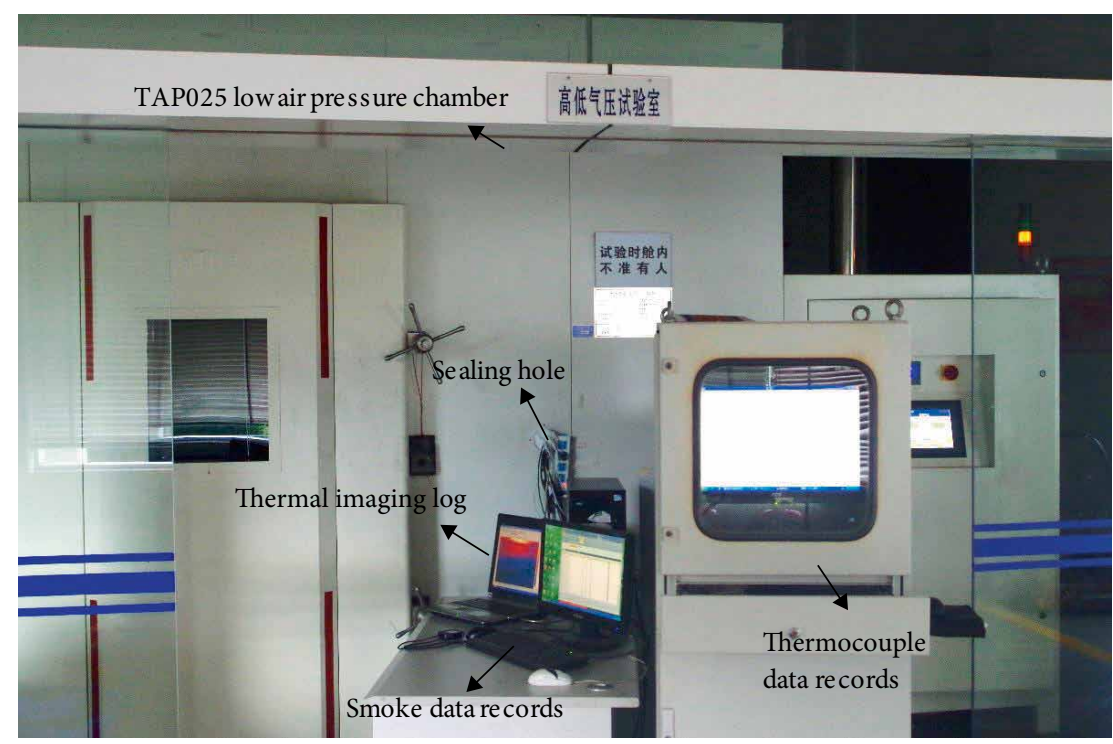

(a)

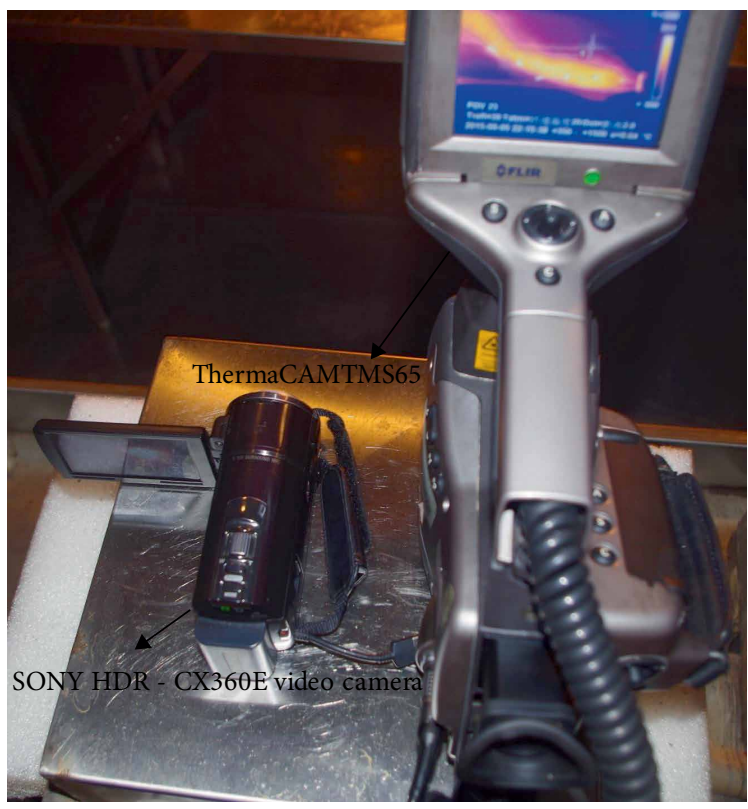

(b)

FIgURE 3: Physical diagram of main experimental equipment: (a) low-pressure test chamber and external apparatus, (b) flame measuring instruments in a low-pressure test chamber.

acquisition system. The material object photo of these instruments and equipment outside the chamber are shown in Figure 3(a). In addition, we use the weighing method to monitor fuel consumption. The thermocouples are fixed on the opening on the rear side wall of the experimental box. And the position of the thermocouples can be adjusted up and down according to the experimental situation so as to test the temperature of the flame trajectory.

For video recording, choose SONY HDR-CX360E video camera and ThermaCAMTMS65, which are located 1.2 meters away from the flame center axis, as shown in Figure 3. The camera records 25 frames per second with a size of 1920 pixels $\times 1080$ pixels. Therma-CAM records 50 frames per second, precision of which is $\pm 2^{\circ} \mathrm{C}$. A thermocouple tree consisting of 6 thermocouples (K type) with a diameter of $0.5 \mathrm{~mm}$ was installed along the axial center line, which was used to calibrate the thermal imager. Thermocouples are also used after calibration.

2.2. Design and Analysis of Experiments. The air volume is adjusted by controlling the damper of the fan, and the ratio of air distribution is adjusted by adjusting the coefficient of air distribution. Therefore, the uniform experimental design in this paper has four factors: fuel injection pressure, throttle opening, air distribution regulation coefficient, and atmospheric pressure. Due to a large number of experimental factors and levels, the uniform experimental design method is adopted in this paper. The uniform design experimentation 
TABLE 1: Plan of the uniform experiment.

\begin{tabular}{lcccc}
\hline Experimental case no. & Fuel injection pressure (MPa) & Throttle opening & $\begin{array}{c}\text { Air distribution condition } \\
\text { coefficient }\end{array}$ & Atmospheric pressure (MPa) \\
\hline 1 & 0.9 & 3 & 3 & 0.10 \\
2 & 1.0 & 5 & 6 & 0.09 \\
3 & 1.1 & 7 & 5 & 0.08 \\
4 & 1.2 & 2 & 1 & 0.07 \\
5 & 1.3 & 4 & 4 & 0.06 \\
6
\end{tabular}

is an experimental design method that only considers the uniform dispersion of test points within the test range [28]. If there are 4 factors in this experiment and 6 levels for each factor, a total of $6^{4}$ (1296) experiments need to be arranged. However, the uniform experimental design only requires these 6 groups of experiments. The uniform experimental design is shown in Table 1.

For the design of uniform experimental scheme, precisely, only a small number of experiments are needed to obtain the degree of influence of each factor on the dependent variable. However, the data processing process of the uniform experiment is more complicated than that of the comprehensive experiment and orthogonal experiment, which requires correlation and multiple regression analysis [29].

Pearson correlation coefficient was used to analyze the correlation between the respective variables and dependent variables. The closer Pearson correlation coefficient is to 1 or -1 , the stronger the correlation, and the closer the correlation coefficient is to 0 , the weaker the correlation. By estimating the covariance and standard deviation of the sample, the Pearson coefficient $(r)$ of the sample can be obtained as follow:

$$
r=\frac{\sum_{i=1}^{n}\left(X_{i}-\bar{X}\right)\left(Y_{i}-\bar{Y}\right)}{\sqrt{\sum_{i=1}^{n}\left(X_{i}-\bar{X}\right)^{2}} \sqrt{\sum_{i=1}^{n}\left(Y_{i}-\bar{Y}\right)^{2}}}
$$

where $X$ refers to the independent variable, $Y$ refers to the dependent variable, and the index $i$ represents the sample number.

2.3. Numerical Method. The macroscopic law of flame change can be obtained from the experimental data. However, it is not enough to explain the mechanism of change by experiment simply. So, the investigation of numerical calculations is obligatory. While most of the other approaches rely on a Eulerian formulation for the continuous and a Lagrangian description for the dispersed phases (Eulerian-Lagrangian), assumed Probability Density Function (PDF) methods are based on Lagrangian-Lagrangian descriptions. Repp et al. [30-32] studied with an assumed PDF model of a turbulent diffusion flame in a closed cyclone-chemical interactions and found that this model has a certain level of accuracy. PDF combustion model differs from the finite rate model; it does not solve transport equations for each component. But by surface flame method (i.e., mixing model that is burning), or to chemical equilibrium calculation process, it has limited advantages over rate model. This model uses a mixed fraction (Mixture Fraction) theory, to simplify the problem of mixing problems, to avoid blocking, understand the difficulties of nonlinear equations of reaction rate, and reduce the computational expense.

In this paper, it is not necessary to analyze the fine structure of flame vortex, but to explain the macro changes of spray flame in plateau environment from the perspective of droplet group combustion. Therefore, the combustion calculation is carried out based on RANS turbulence approach and non premixed combustion equilibrium chemical reaction.

For unsteady two-phase combustion, the governing equation of the droplet surface should be as follows:

$$
\begin{gathered}
\rho_{\mathrm{g}} v_{g, n}=\rho_{g} v_{g, n} Y_{f}-\rho_{g} D_{g}\left(\frac{d Y_{f}}{d r_{s}}\right), \\
\rho_{g} v_{g, n} Y_{o}=\rho_{g} D_{g}\left(\frac{d Y_{o}}{d r_{s}}\right), \\
v_{g, \theta}=v_{l, \theta}, \\
\mu_{g}\left(\frac{\partial v_{\theta}}{\partial r}-\frac{v_{\theta}}{r}+\frac{1}{r} \frac{\partial v_{n}}{\partial r}\right)=\mu_{l}\left(\frac{\partial v_{\theta}}{\partial r}-\frac{v_{\theta}}{r}+\frac{1}{r} \frac{\partial v_{n}}{\partial r}\right)_{l} \\
\lambda_{g}\left(\frac{d T}{d r_{s}}\right)=\rho_{g} v_{g, n} L-\lambda_{l}\left(\frac{d T}{d r_{s}}\right), \\
\ln \left(\frac{p_{s}}{p_{r e f}}\right)=\frac{L}{R}\left(\frac{1}{T_{r e f}}-\frac{1}{T}\right) .
\end{gathered}
$$

In the above formulas, $v$ is vertical velocity of the droplets; $T$ is temperature; $p$ is pressure; $\rho$ is the density; $Y$ is the mass fraction; $D$ is diffusion coefficient; $r$ is droplet radius; $\mu$ is dynamic viscosity; $\lambda$ is the thermal conductivity; $L$ is droplets latent heat of vaporization. Wherein the subscript: $l$ refers to liquid; $g$ refers to vapor; $n$ and $\theta$ refer to the normal direction and peripheral direction, respectively; $o$ is oxidant; $f$ is fuel; $s$ refers to the spherical surface of the liquid droplet.

Phase-to-phase coupling calculation can be considered in transient flow. In each iteration time step, the continuous phase and discrete phase are selected to conduct a coupling calculation every 40 steps. For the numerical calculations in this article, the components will be simplified into a single light diesel fuel component $\mathrm{C}_{12} \mathrm{H}_{23}$. In order to consider the 


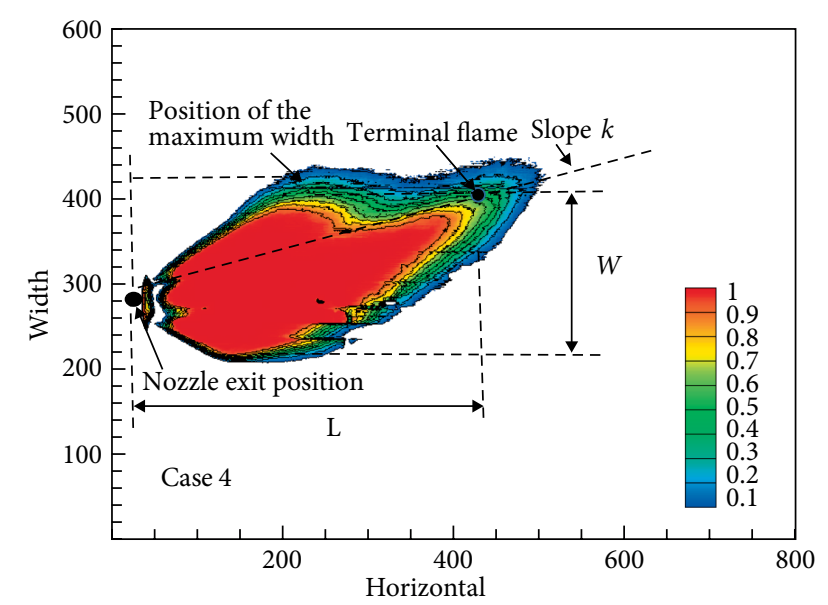

FIGURE 4: Flame probability characteristic parameter definition diagram.

influence of turbulence on the randomness of particles, the random orbit model is adopted. To ensure the randomness of the droplet trajectory, a total of 3,600 particles were uniformly distributed within a $360^{\circ}$ range.

In addition, to explain the changing mechanism by numerical simulation method, the spray size distribution range of this spray combustion should be investigated. The atomizing particle size of the Riello G5 type burner is tested with a Winner318A Mastersizer [33]. Through the test experiment of spray size distribution, the results show that the spray particle size of the burner is distributed in the range of 20 60 microns. Droplets within this size range are selected for analysis in this paper. The actual measured spray particle size range is applied to the numerical simulation and then the change mechanism of flame at a low-pressure environment can be explained from the perspective of the droplet combustion.

\section{Results and Discussion}

Compared with gas combustion or in normal pressure, the $n$-heptane fuel burning process is more complicated, especially with a sub-atmospheric pressure. The flame shape, especially the flame uplifted characteristic, is significant to the engineering design of burner and heater. The flame temperature determines the quality of combustion and the utilization of heat, and the emission of NO is the decisive standard of whether the whole burner can be used in the plateau because the national pollutant emission standard must be met. All these critical characteristics discussed are of great practical significance for the design and use of burners in the plateau. The uniform experimental results and correlation analysis were obtained, and the spray combustion at low pressure was explained from the perspective of droplet microstructure.

3.1. Flame Shape. The flame shape is one of the most important and intuitive characteristics of combustion characteristics [34]. The flame video recorded in the low-pressure chamber was processed with grayscale and binarization $[35,36]$. The selection of threshold is the key work of flame binarization. Otsu' method is widely used in flame image processing $[37,38]$. Through the binary processing of flame video, the probability distribution contour of flame morphology was obtained by calculating the probability of bright spots appearing in the continuous sequence of flame images [39]. Taking working condition 4 as an example, the flame shape parameters are defined as shown in Figure 4, where $L$ is the flame length and $W$ is the maximum flame width. In addition, the position of the nozzle and the position of the terminal flame are also revealed. Slope $k$ represents the magnitude of horizontal flame uplifted. The definition of flame trajectories is widely used in this kind of flame with upward bending, and the definition method here is the same as in the literature [40].

Figure 5 was obtained by image processing of flame probability distribution from experimental cases 1-6. Through direct observation, we can see that the flame morphological changes are relatively small in experimental conditions $1-3$. In experimental conditions 4 and 6 , the terminal flame presents a strong horizontal uplifted characteristic. This is mainly caused by a decrease in air volume and atmospheric pressure. At different environmental pressures, change in the air density causes a strong flame uplifted characteristic. However, the experimental case 5 showed that the flame width was obviously prominent in the middle region. This should be caused by the adjustment of the air distribution coefficient. Therefore, the adjustment of the air distribution ratio is an effective method under low atmospheric pressure. The specific influencing factors also require regression analysis, which will be calculated in the following sections.

\subsection{Trajectory Axial Temperature Distribution. The} temperature distributions measured on the flame trajectories in the six groups of uniform experiments are shown in Figure 6. In addition, dimensionless analysis of temperature distribution is required due to the change of air density. The resulting transformation is shown in Figure 7. In this process, the dimensionless analysis method of $\mathrm{Hu}$ et al. was adopted [41], the temperature rise was taken as the dependent variable, and air density was brought into the dimensionless power term for normalization. According to Xie et al's three-region theory of horizontal spray flame [42], it can be seen that the temperature value in the continuous flame region remains basically the same except case 6. Due to different operating parameters and atmospheric pressure, different degrees of temperature rise are observed in the region of buoyancy plume flame.

The axial temperature distribution is usually scaled by $Z / Z^{*}$ [43], where $Z$ is introduced as a characteristic vertical length in flame scaling [44]. For horizontal jet flames [45, 46] and buoyancy type flame $[47,48]$, we always focus on the temperature distribution of the trajectory axial [49]. To include the pressure effect in the analysis of trajectory axial temperature, the characteristic horizontal length should be further suggested as $X^{*}$, namely $\left(X-X_{0}\right) / D$. Physically, the virtual origin is used to account for the different buoyancy flux at the source. In this paper, the virtual origin refers to the position of the nozzle exit. With accounting for the virtual origin [41], then the trajectory axial temperature distribution measured data can be correlated non dimensional by the normalization of: 

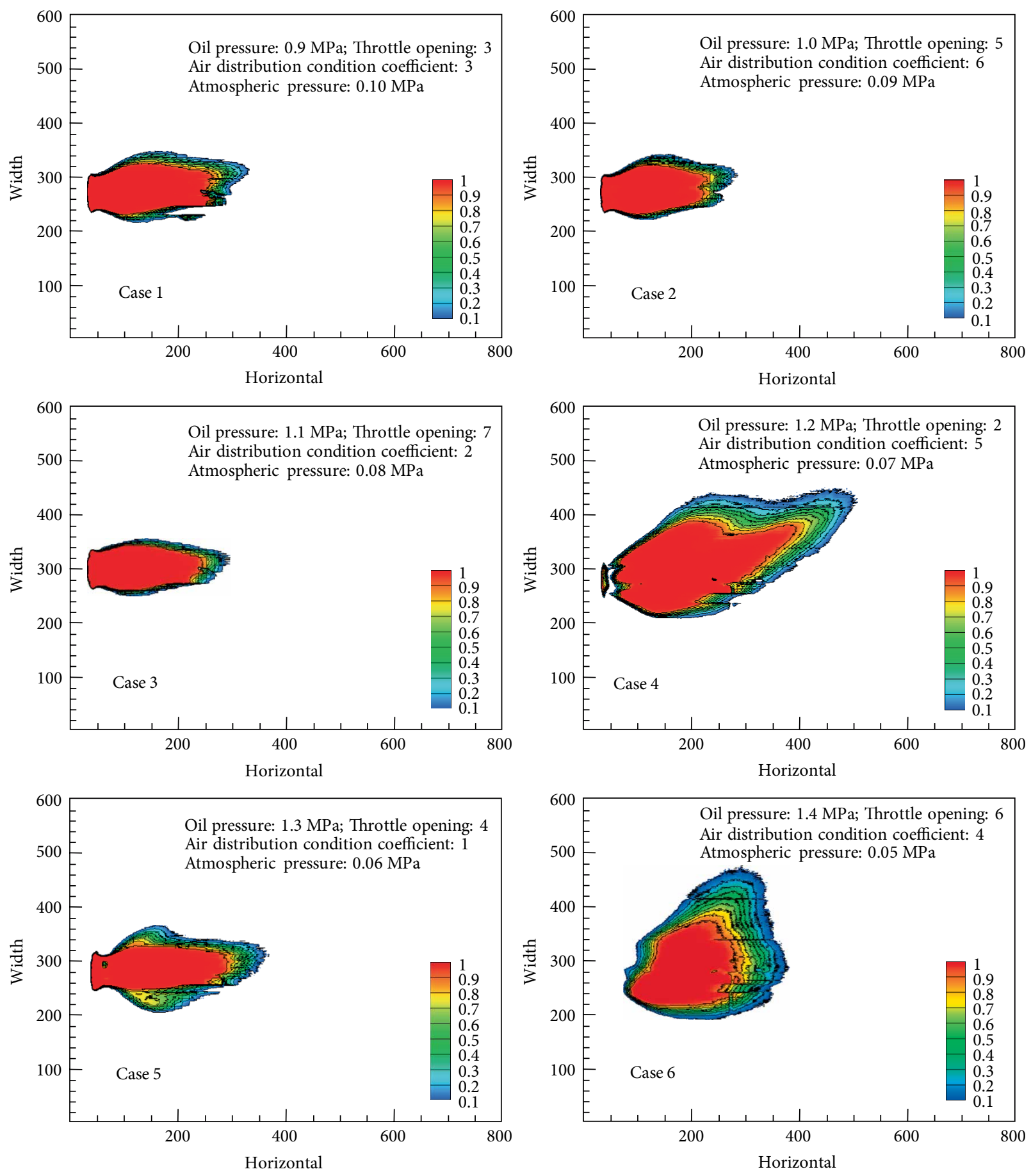

FIGURE 5: Probability distribution contour of flame morphology.

$$
\frac{\left(T-T_{0}\right)}{T_{0}} \text { versus } \frac{\left(X-X_{0}\right) / D}{Q^{* 2 / 5}} .
$$

3.3. NO Emission. The measurement and control of harmful pollutants in combustion equipment are one of the important characteristics of a combustion process. The nitrogen oxide produced in the combustion reaction of light diesel is mainly NO. NO emission data of experimental cases 1-6 are shown in Figure 8. For spray combustion, generally, the increase in fuel injection pressure will not result in the increase in pollutant emission. In experiments 4-6, the emission concentration of NO significantly increases, which may be directly analyzed as the result of the decrease in environmental pressure. In addition, we note that the damper opening degree in experimental condition 4 is minimal, which means that the air volume at this time is minimal, and the air volume at this time cannot guarantee the full combustion of fuel, which is one of the reasons for the largest concentration of NO. In addition, NO is mainly thermal type NO, which is mainly related to the combustion temperature. Generally speaking, 


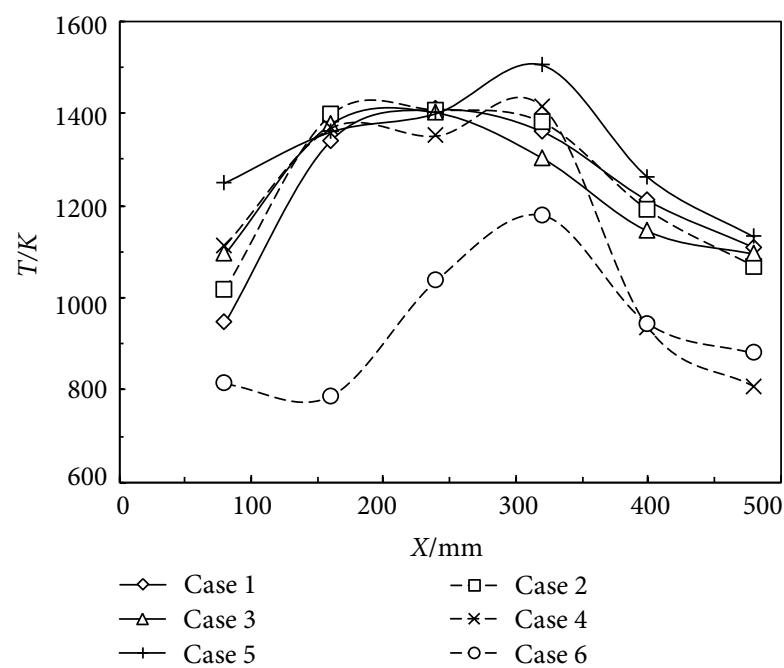

FIGURE 6: The actually measured temperature distribution on the flame trajectory.

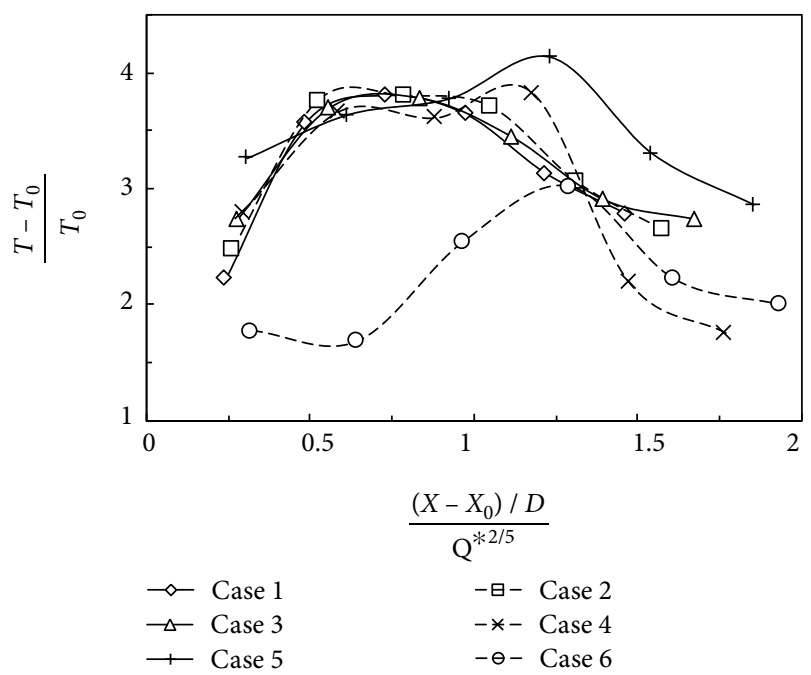

Figure 7: The dimensionless temperature distribution on the flame trajectory.

the higher the combustion temperature, the higher the NO concentration will be. In order to reduce $\mathrm{NO}$ emission in the combustion of the plateau environment, the temperature in the secondary high-temperature reaction zone of the flame should be controlled.

3.4. Correlation and Regression Analysis. According to the proportion of pixels in the image in the previous section to the actual size, the flame length, flame width, maximum flame width position, and the slope of flame uplifted height characteristics of each experimental condition can be calculated. The data are shown in Table 2.

In this section, we conducted correlation and multiple regression analysis on flame length, flame width, flame maximum width position, the slope of flame uplifted characteristic and $\mathrm{NO}$ emission, respectively.

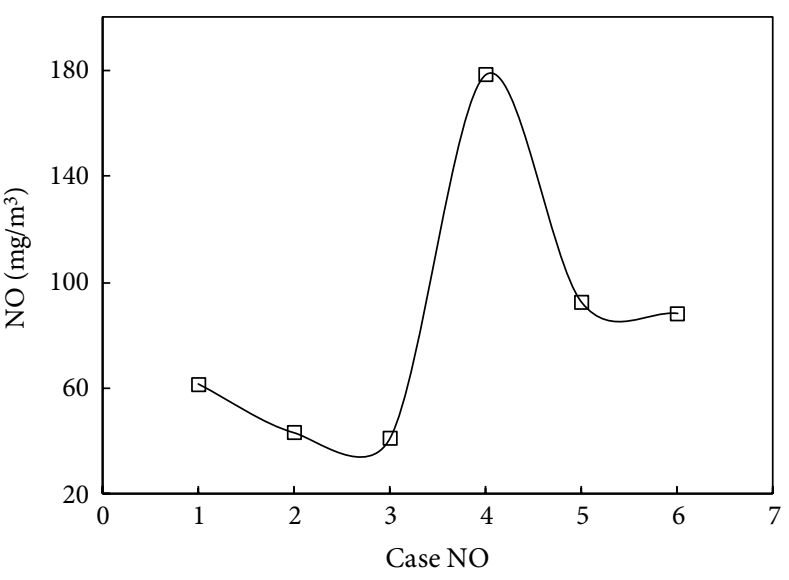

FIGURE 8: NO emission concentration.

The correlation analysis table of each dependent variable and four independent variables calculated finally is shown in Table 3. As can be seen, air volume mainly affects the flame length and $\mathrm{NO}$ emission. With the decrease in air volume, flame length becomes longer and NO emission increases greatly. In addition to being most affected by air volume, NO emission is also positively and negatively correlated with fuel injection pressure and atmospheric pressure, respectively. The maximum flame width and its position are positively and negatively correlated with fuel injection pressure and atmospheric pressure respectively. In addition, the slope of flame uplifted height characteristic is closely related to the operating parameters and atmospheric pressure, and the distinction between primary and secondary factors is not obvious.

The regional temperatures of horizontal spray flame are related to different independent variables. It is obvious that atmospheric pressure mainly affects the temperature rise in the continuous flame region and the buoyancy plume region. The flame temperature in the recirculation region is most affected by air distribution. The influence of fuel injection pressure and atmospheric pressure on the temperature of the continuous flame region is most significant. However, the temperature of the buoyancy flame region is almost affected equally by various factors, which means that the temperature rise mechanism in the buoyancy flame region is very complicated.

Especially for atmospheric pressure, it is negatively correlated with the characteristic parameters of each flame. That is to say, in the plateau environment, the flame length and width of horizontal spray combustion fuel burner become longer, and the flame has obvious uplifted characteristics, and the emission of NO increases. This may be mainly due to the uplifted effect at terminal flame region caused by the increase in combustion temperature in the low-density atmosphere. In addition, the increase in temperature will lead to the obvious increase in thermal NO and eventually lead to an increase in NO emission.

Finally, the following regression equations were obtained by the regression calculation of these dependent variables. Since the temperature value is only a measurement point on the flame trajectory, its regression equation is not of great significance and is not listed here. 
TABle 2: Flame characteristic data.

\begin{tabular}{lcccc}
\hline Experimental no. & Flame length $(\mathrm{mm})$ & Maximum fame width $(\mathrm{mm})$ & $\begin{array}{c}\text { Maximum flame width } \\
\text { position }(\mathrm{mm})\end{array}$ & $\begin{array}{c}\text { The slope of flame uplifted } \\
\text { height characteristics }\end{array}$ \\
\hline 1 & 278.2 & 105.8 & 133.8 & 0.145 \\
2 & 239.2 & 101.6 & 114.9 & 0.142 \\
3 & 255.0 & 88.9 & 117.0 & 0.071 \\
4 & 429.0 & 188.4 & 203.4 & 0.279 \\
5 & 310.0 & 132.3 & 127.5 & 0.099 \\
6 & 257.1 & 194.7 & 213.9 & 0.280 \\
\hline
\end{tabular}

TABLE 3: Correlation datasheet.

\begin{tabular}{|c|c|c|c|c|c|c|c|c|}
\hline & Flame length & $\begin{array}{l}\text { Maximum } \\
\text { flame width }\end{array}$ & $\begin{array}{c}\text { Maximum } \\
\text { flame width } \\
\text { position }\end{array}$ & Slope $k$ & NO emission & $\begin{array}{c}\text { Recirculation } \\
\text { region }\end{array}$ & $\begin{array}{l}\text { Temperature } \\
\text { Continuous } \\
\text { flame region }\end{array}$ & $\begin{array}{c}\text { Buoyancy } \\
\text { plume region }\end{array}$ \\
\hline $\begin{array}{l}\text { Fuel injection } \\
\text { pressure }\end{array}$ & 0.214 & 0.741 & 0.627 & 0.449 & 0.438 & 0.020 & -0.700 & -0.507 \\
\hline $\begin{array}{l}\text { Throttle } \\
\text { opening }\end{array}$ & -0.765 & -0.305 & -0.244 & -0.351 & -0.687 & -0.255 & -0.311 & 0.258 \\
\hline $\begin{array}{l}\text { Air distribu- } \\
\text { tion condition } \\
\text { coefficient }\end{array}$ & 0.112 & 0.273 & 0.330 & 0.580 & 0.202 & -0.439 & -0.176 & -0.474 \\
\hline $\begin{array}{l}\text { Atmospheric } \\
\text { pressure }\end{array}$ & -0.214 & -0.741 & -0.627 & -0.449 & -0.438 & -0.020 & 0.700 & 0.507 \\
\hline
\end{tabular}

Equations (9)-(13) are the multiple linear regression equations of flame length, maximum flame width, maximum flame width position, the slope of flame uplifted height characteristics, and NO emission, respectively.

$$
\begin{aligned}
\hat{y}_{1} & =262.0+147.3 x_{1}-31.42 x_{2}+0.807 x_{3}+25.78 x_{4}, \\
R & =0.85, \\
\hat{y}_{2} & =37.12+145.6 x_{1}-10.06 x_{2}+9.070 x_{3}-74.39 x_{4}, \\
R & =0.94 \\
\hat{y}_{3} & =-57.20+182.3 x_{1}-7.520 x_{2}+10.09 x_{3}-28.86 x_{4}, \\
R & =0.84 \\
\hat{y}_{4} & =-0.1634+0.2816 x_{1}-0.0170 x_{2}+0.0306 x_{3}-0.2911 x_{4}, \\
R & =0.89, \\
\hat{y}_{5} & =-29.49+169.09 x_{1}-21.23 x_{2}+4.686 x_{3}-22.29 x_{4}, \\
R & =0.92,
\end{aligned}
$$

where, $x_{1}$ is the fuel injection pressure, $x_{2}$ is the throttle opening, $x_{3}$ is the air distribution condition, and $x_{4}$ is the Atmospheric pressure, $R$ is the correlation coefficients.

For engineering experiments, $a$ is given to be 0.1 (i.e., $90 \%$ confidence level). Regression equation tests were carried out for the Equations (9)-(13), respectively, and the test results were all significant, indicating that the above regression equation was meaningful. The following conclusions are obtained by testing whether the variables in each regression equation have a significant influence on the regression equation. The flame length is mainly affected by fuel injection pressure, valve opening and atmospheric pressure. In Equation
(9), the regression equation of flame length is significantly affected by fuel injection pressure, throttle opening and atmospheric pressure. That is to say, the flame length is mainly determined by them and is not closely related to the air distribution condition coefficient. In Equations (10) and (11), the four dependent variables have significant effects on the maximum width and position of the flame. For the flame uplifted characteristic of Equation (12), fuel injection pressure and atmospheric pressure have the most significant influence on it. In Equation (13), NO emission is mainly affected by fuel injection pressure, wind door opening and atmospheric pressure.

\subsection{Analysis of the Droplets Burning}

3.5.1. Droplet Burning Time. Figure 9(a) shows the burning time of droplets with different particle sizes under different ambient pressures. The general trend of droplets burning time under different atmospheric pressures is approximately the same. For droplets of a given size, the lower the pressure, the longer the droplet burning time. In addition, with the increase in droplet size, the burning time of droplet increases greatly, which basically conforms to $d^{2}$ saw. The average dimensionless burning time of all the droplets under different atmospheric pressures were calculated, as shown in Figure 9(b). Here, $P^{*}=P / P_{0}, P_{0}$ is atmospheric pressure. $t^{*}=t / t_{0}, t_{0}$ is the average burning time of the droplets at normal pressure. There is a linear negative correlation between average burning time and atmospheric pressure. The average burning time at $0.05 \mathrm{MPa}$ was nearly $100 \%$ higher than that at normal pressure. This is because the pressure is directly related to the oxygen content in the combustion space. The lower the pressure is, 


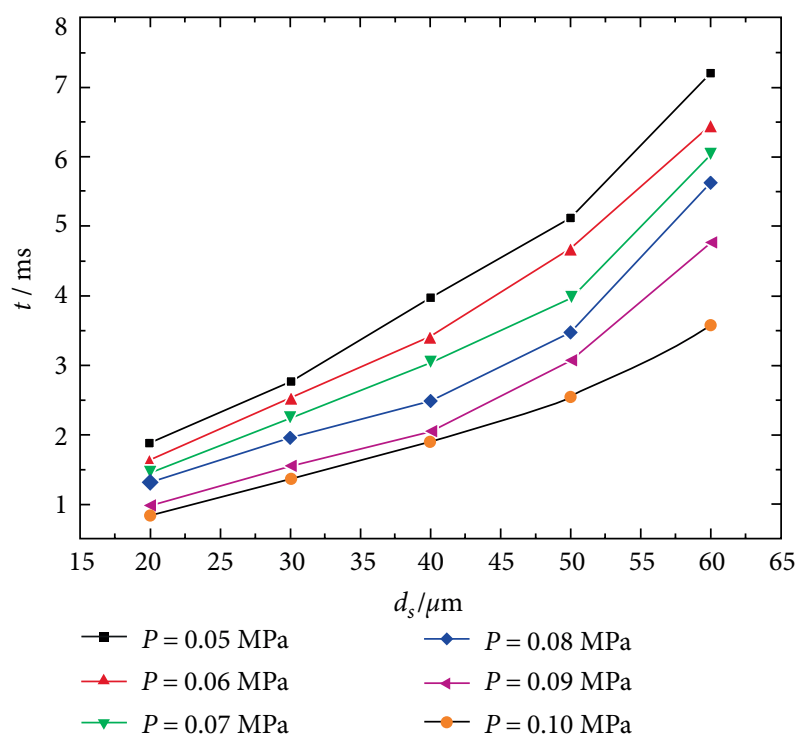

(a)

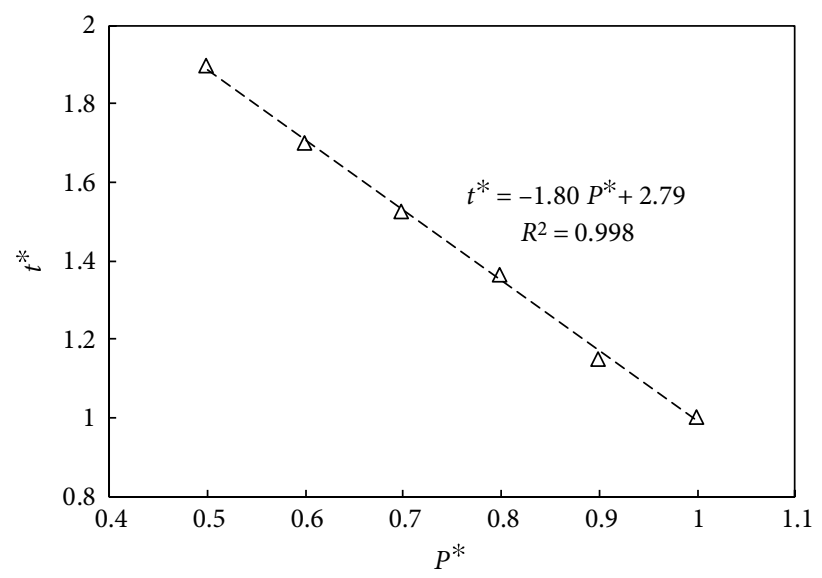

(b)

Figure 9: The burning time of the droplets: (a) droplets of different sizes under different atmospheric pressures, (b) the relationship between the average dimensionless burning time of all droplet sizes and atmospheric pressure.

the lower the oxygen content in the air will be. Therefore, the chemical reaction rate between droplets and air will be slower, leading to an increase in the burning time of droplets with the same size and particle size in the environment of low pressure.

3.5.2. Droplet Burning Path. The combustion paths of droplets of different sizes under different atmospheric pressures are shown in Figure 10(a). The changing trend of droplet burning path is consistent with droplet combustion time. With the decrease in atmospheric pressure, the burning path increases obviously. Moreover, the average droplet paths of all sizes were calculated, and the dimensionless results are shown in Figure $10(\mathrm{~b})$. Here, $L^{*}=L / L_{0}, L_{0}$ is the average burning path of the droplets at normal pressure. The droplet average dimensionless burning path varies with -0.63 power law of atmospheric pressure, which is consistent with the relation

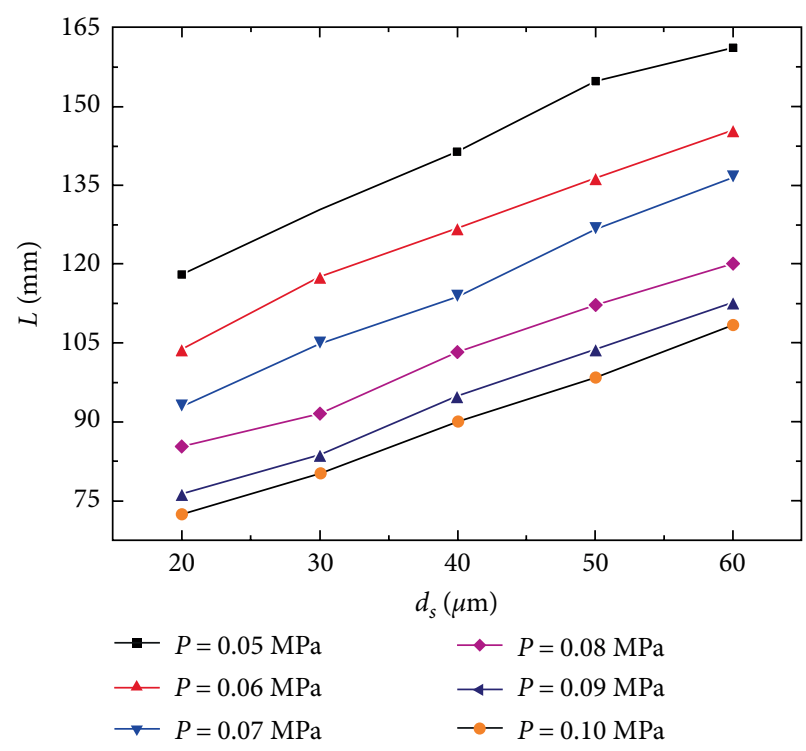

(a)

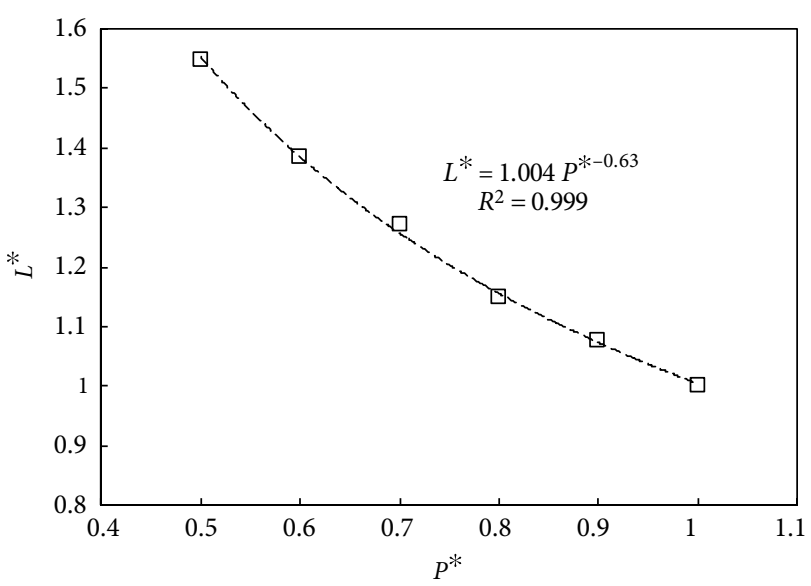

(b)

FIGURE 10: The burning path of the droplets: (a) droplets of different sizes under different atmospheric pressures, (b) the relationship between the average dimensionless burning path of all droplet sizes and atmospheric pressure.

between flame length and atmospheric pressure [50]. At $0.05 \mathrm{MPa}$ atmospheric pressure, the average droplet burning path increased by $55 \%$ compared with that at normal pressure. The increase in droplet burning time and movement path also reflects the correctness of the conclusion that flame length increases under low-pressure.

At the micro level of the droplet, the flame morphology becomes longer and wider due to the increase in the average burning time and path of the droplet. This also confirms that the final flame shape of spray combustion is determined by the combustion state of droplets. According to the previous uniform experiment results, in the plateau environment, the change of droplet combustion state caused by air density can be compensated by the change of operating parameters. Whether it is to increase the fuel injection pressure, increase the air intake, or change the air distribution ratio, these are all measures taken to promote the burning of droplets. The 
experimental results in this paper prove that this is an effective method on the plateau.

\section{Conclusions}

In this paper, the uniform experimental design of different burner operating parameters and atmospheric pressure were carried out, and the combustion experiments were completed in a low-pressure chamber. The combustion characteristics of horizontal spray flame such as flame length, maximum flame width, and its position, the slope of flame uplifted height characteristics, the temperature distribution of the flame trajectory, and $\mathrm{NO}$ emission concentration were obtained.

The main and secondary influencing factors of the combustion characteristics were obtained through the phase relationship analysis. For the combustion in the plateau environment, the maximum width and position of flame are most closely related to atmospheric pressure. NO emission and flame horizontal uplifted characteristics are also closely related to atmospheric pressure. In the plateau environment, flame morphology can be adjusted by increasing fuel injection pressure and changing the ratio of air distribution, and NO emission can be kept at a low concentration. This provides a reliable experimental basis for the single-factor experimental design of horizontal spray jet combustion under sub-atmospheric pressure. In the low-pressure environment, both burning time and burning path of diesel droplets are longer at $0.05 \mathrm{MPa}$ than that at $0.10 \mathrm{MPa}$. Burning path increased by $55 \%$, which in accordance with flame growth extent. At the same time, burning time increased by nearly $100 \%$.

\section{Data Availability}

For data availability, if the researcher needs data of this article, the corresponding author can provide the experiment data.

\section{Conflicts of Interest}

The authors declare that there are no conflicts of interest regarding the publication of this paper.

\section{Acknowledgments}

This research was supported by the National Key R\&D Program of China under Grant No. 2017YFC0806303.

\section{References}

[1] A. H. Lefebvre and V. G. McDonell, Atomization and Sprays, CRC Press, pp. 56-57, 2017.

[2] Z. Musavi, H. Kusar, R. Andersson, and K. Engvall, "Modelling and optimization of a small diesel burner for mobile applications," Energies, vol. 11, no. 11, pp. 2904-2925, 2019.

[3] D. W. Wekesa, C. Wang, and Y. Wei, "Empirical and numerical analysis of small wind turbine aerodynamic performance at a plateau terrain in Kenya," Renewable Energy, vol. 90, pp. 377-385, 2016.
[4] L. Iral and A. Amell, "Performance study of an induced air porous radiant burner for household applications at high altitude," Applied Thermal Engineering, vol. 83, pp. 31-39, 2015.

[5] L. H. Hu, Q. Wang, M. Delichatsios, F. Tang, X. Zhang, and S. Lu, "Flame height and lift-off of turbulent buoyant jet diffusion flames in a reduced pressure atmosphere," Fuel, vol. 109, pp. 234-240, 2013.

[6] Y. Li, H. Guo, X. Ma, J. Wang, and H. Xu, "Droplet dynamics of DI spray from sub-atmospheric to elevated ambient pressure," Fuel, vol. 179, pp. 25-35, 2016.

[7] J. Sun, Z. Shen, L. Zhang et al., " Impact of primary and secondary air supply intensity in stove on emissions of sizesegregated particulate matter and carbonaceous aerosols from apple tree wood burning," Atmospheric Research, vol. 202, pp. 33-39, 2018.

[8] X. Zhang, L. H. Hu, X. Zhang, L. Yang, and S. Wang, "Nondimensional correlations on flame height and axial temperature profile of a buoyant turbulent line-source jet fire plume," Journal of Fire Sciences, vol. 32, no. 5, pp. 406-416, 2014.

[9] H. Li, Z. Zhou, Y. Niu, J. Yao, D. Zhou, and J. Wang, "Effect of pressure and type of fuel on laminar diffusion flame height at subatmospheric pressures," Chemistry and Technology of Fuels and Oils, vol. 51, pp. 389-396, 2015.

[10] L. H. Hu, X. Zhang, X. Zhang, K. Lu, and Z. Guo, "Flame heights and fraction of stoichiometric air entrained for rectangular turbulent jet fires in a sub-atmospheric pressure," Proceedings of the Combustion Institute, vol. 36, no. 2, pp. 2995-3002, 2017.

[11] Q. Wang, F. Tang, H. Liu, Z. Zhou, and A. Palacios, "Experimental investigation on the effect of a reduced pressure on the combustion characteristics and flame height of gaseous fuel jets in parallel sidewalls," Energy \& Fuels, vol. 32, no. 2, pp. 2490-2496, 2018.

[12] F. Tang, K. Zhu, M. Dong, and Q. Shi, "Mean flame height and radiative heat flux characteristic of medium scale rectangular thermal buoyancy source with different aspect ratios in a subatmospheric pressure," International Journal of Heat and Mass Transfer, vol. 84, pp. 427-432, 2015.

[13] J. M. Most, P. Mandin, J. Chen, P. Joulain, D. Durox, and A. C. Fernande-Pello, "Influence of gravity and pressure on pool fire-type diffusion flames," Symposium (International) on Combustion, vol. 26, no. 1, pp. 1311-1317, 1996.

[14] D. Wieser, P. Jauch, and U. Willi, "The influence of high altitude on fire detector test fires," Fire Safety Journal, vol. 29, no. 2-3, pp. 195-204, 1997.

[15] Z. Tao, R. Yang, C. Li, Y. Yao, P. Zhang, and H. Zhang, "An experimental study on fire behavior of an inclined ceiling jet in a low-pressure environment," International Journal of Thermal Sciences, vol. 138, pp. 487-495, 2019.

[16] J. Liu, Y. He, Z. Zhou, W. Yao, R. Yuen, and J. Wang, "The burning behaviors of pool fire flames under low pressure," Fire and Materials, vol. 40, no. 2, pp. 318-334, 2016.

[17] Z. H. Li, Y. He, H. Zhang, and J. Wang, "Combustion characteristics of n-heptane and wood crib fires at different altitudes," Proceedings of the Combustion Institute, vol. 32, no. 2, pp. 2481-2488, 2009.

[18] X. Zhang, L. Hu, W. Zhu, X. Zhang, and L. Yang, "Axial temperature profile in buoyant plume of rectangular source fuel jet fire in normal-and a sub-atmospheric pressure," Fuel, vol. 134, pp. 455-459, 2014.

[19] J. H. Liu, P. Li, M. Y. Chen, X. Chen, R. Yuen, and J. Wang, "Experimental study on burning behaviors of liquid fuels with 
different sooting levels at high altitude," Thermal Science, vol. 21, no. 6 Part A, pp. 2533-2541, 2017.

[20] X. Hu, Y. He, Z. Li, and J. Wang, "Combustion characteristics of n-heptane at high altitudes," Proceedings of the Combustion Institute, vol. 33, no. 2, pp. 2607-2615, 2011.

[21] S. Zadmajid, S. Albert-Green, Y. Afarin, and M. J. Thomson, "Optimizing a swirl burner for pyrolysis liquid biofuel (bio-oil) combustion without blending," Energy \& Fuels, vol. 31, no. 6, pp. 6065-6079, 2017.

[22] I. R. Fattah, C. Ming, Q. N. Chan et al., "Spray and combustion investigation of post injections under low-temperature combustion conditions with biodiesel," Energy \& Fuels, vol. 32, no. 8, pp. 8727-8742, 2018.

[23] T. Badawy, M. Hamza, A. Ahmad, M. S. Mansour, A. H. H. Abdel-Hafez, and H. Imam, "New developed burner towards stable lean turbulent partially premixed flames," Fuel, vol. 220, pp. 942-957, 2018.

[24] Y. Zhou, X. Huang, S. Peng, and L. Li, "Comparative study on the combustion characteristics of an atmospheric induction stove in the plateau and plain regions of China," Applied Thermal Engineering, vol. 111, pp. 301-307, 2017.

[25] J. W. Wang, J. Fang, J. F. Guan, Y. Zeng, and Y. M. Zhang, "Flame volume and radiant fraction of jet diffusion methane flame at sub-atmospheric pressures," Fuel, vol. 167, pp. 82-88, 2016.

[26] Q. Wang, L. Hu, M. Zhang, F. Tang, X. Zhang, and S. Lu, "Lift-off of jet diffusion flame in sub-atmospheric pressures: An experimental investigation and interpretation based on laminar flame speed," Combustion and Flame, vol. 161, no. 4, pp. 1125-1130, 2014.

[27] J. Chang, J. Wang, Z. Wang, S. Shan, and C. Liu, "Analysis of converter combustion flame spectrum big data sets based on HHT,' Complexity, vol. 2018, pp. 1-11, Article ID 8682725, 2018.

[28] Z.-K. Feng, W.-J. Niu, and C.-T. Cheng, "Optimizing electrical power production of hydropower system by uniform progressive optimality algorithm based on two-stage search mechanism and uniform design," Journal of Cleaner Production, vol. 190, pp. 432-442, 2018.

[29] A. Wosiak and D. Zakrzewska, "Integrating correlation-based feature selection and clustering for improved cardiovascular disease diagnosis," Complexity, vol. 2018, pp. 1-11, Article ID 2520706, 2018.

[30] S. Repp, A. Sadiki, C. Schneider, A. Hinz, T. Landenfeld, and J. Janicka, "Prediction of swirling confined diffusion flame with a Monte Carlo and a presumed-PDF-model," International Journal of Heat and Mass Transfer, vol. 45, no. 6, pp. 1271-1285, 2002.

[31] A. Khelil, H. Naji, L. Loukarfi, and G. Mompean, "Prediction of a high swirled natural gas diffusion flame using a PDF model," Fuel, vol. 88, no. 2, pp. 374-381, 2009.

[32] F. Bazdidi-Tehrani and H. Zeinivand, "Presumed PDF modeling of reactive two-phase flow in a three dimensional jet-stabilized model combustor," Energy Conversion and Management, vol. 51, no. 1, pp. 225-234, 2010.

[33] K. Xie, X. Q. Qiu, Y. J. Cui, and J. X. Wang, “Theoretical and experimental study on spatial distribution characteristics of diesel spray particle size (in Chinese)," Journal of Engineering Science and Technology, vol. 19, pp. 88-93, 2019.

[34] Z. Xi, Z. Fu, X. Hu, S. Sabir, and Y. Jiang, "An investigation on flame shape and size for a high-pressure turbulent nonpremixed swirl combustion," Energies, vol. 11, no. 4, p. 930, 2018.
[35] M. Yang, Y. Bian, J. Yang, and G. Liu, "Combustion state recognition of flame images using radial Chebyshev moment invariants coupled with an IFA-WSVM model," Applied Sciences, vol. 8, no. 11, p. 2331, 2018.

[36] J. W. Wang, J. Fang, S. B. Lin, J. F. Guan, Y. M. Zhang, and J. J. Wang, "Tilt angle of turbulent jet diffusion flame in crossflow and a global correlation with momentum flux ratio," Proceedings of the Combustion Institute, vol. 36, no. 2, pp. 2979-2986, 2017.

[37] X. Zhang, L. Hu, W. Zhu, X. Zhang, and L. Yang, "Flame extension length and temperature profile in thermal impinging flow of buoyant round jet upon a horizontal plate," Applied Thermal Engineering, vol. 73, no. 1, pp. 15-22, 2014.

[38] X. Zhang, H. Tao, W. Xu et al., "Flame extension lengths beneath an inclined ceiling induced by rectangular-source fires," Combustion and Flame, vol. 176, pp. 349-357, 2017.

[39] P. He, P. Wang, K. Wang et al., "The evolution of flame height and air flow for double rectangular pool fires," Fuel, vol. 237, pp. 486-493, 2019.

[40] X. Zhang, W. Xu, L. Hu, X. Liu, X. Zhang, and W. Xu, "A new mathematical method for quantifying trajectory of buoyant line-source gaseous fuel jet diffusion flames in cross air flows," Fuel, vol. 177, pp. 107-112, 2016.

[41] L. H. Hu, Q. Wang, F. Tang, M. Delichatsios, and X. C. Zhang, "Axial temperature profile in vertical buoyant turbulent jet fire in a reduced pressure atmosphere," Fuel, vol. 106, pp. 779-786, 2013.

[42] K. Xie, X. Q. Qiu, Y. J. Cui, and J. X. Wang, "Experimental study on the effect of spray cone angle on the characteristics of horizontal jet spray flame under sub-atmospheric pressure," Thermal Science, 2019.

[43] J. G. Quintiere and B. S. Grove, "A unified analysis for fire plumes," Symposium (International) on Combustion, vol. 27, no. 2, pp. 2757-2766, 1998.

[44] G. Heskestad, "Fire plumes, flame height, and air entrainment," in SFPE Handbook of Fire Protection Engineering, Springer, New York, USA, pp. 396-428, 2016.

[45] T. Smith, C. Periasamy, B. Baird, and S. R. Gollahalli, “Trajectory and characteristics of buoyancy and momentum dominated horizontal jet flames from circular and elliptic burners," Journal of Energy Resources Technology, vol. 128, no. 4, pp. 300-310, 2006.

[46] J. J. Heffernen, C. R. Hartsfield, M. F. Reeder, and M. D. Polanka, "Horizontally issuing diffusion flames characterized by $\mathrm{OH}-$ PLIF and visualizations," International Journal of Spray and Combustion Dynamics, vol. 6, no. 1, pp. 35-66, 2014.

[47] J. S. Kim, W. Yang, Y. Kim, and S. H. Won, "Behavior of buoyancy and momentum controlled hydrogen jets and flames emitted into the quiescent atmosphere," Journal of Loss Prevention in the Process Industries, vol. 22, no. 6, pp. 943-949, 2009.

[48] C. F. Tao, Y. Shen, R. W. Zong, and F. Tang, "An experimental study of flame height and air entrainment of buoyancycontrolled jet flames with sidewalls," Fuel, vol. 183, pp. 164-169, 2016.

[49] C. Tao, Y. Shen, and R. Zong, "Experimental determination of flame length of buoyancy-controlled turbulent jet diffusion flames from inclined nozzles," Applied Thermal Engineering, vol. 93, pp. 884-887, 2016.

[50] K. Xie, X. Q. Qiu, and Y. J. Cui, “Experimental study on flame morphology of horizontal jet spray combustion in low pressure environment (in Chinese)," Industrial Heating, vol. 47, pp. 8-12, 2018. 


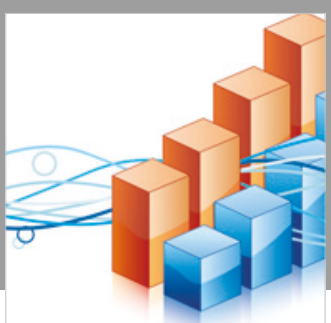

Advances in

Operations Research

\section{-n-m}
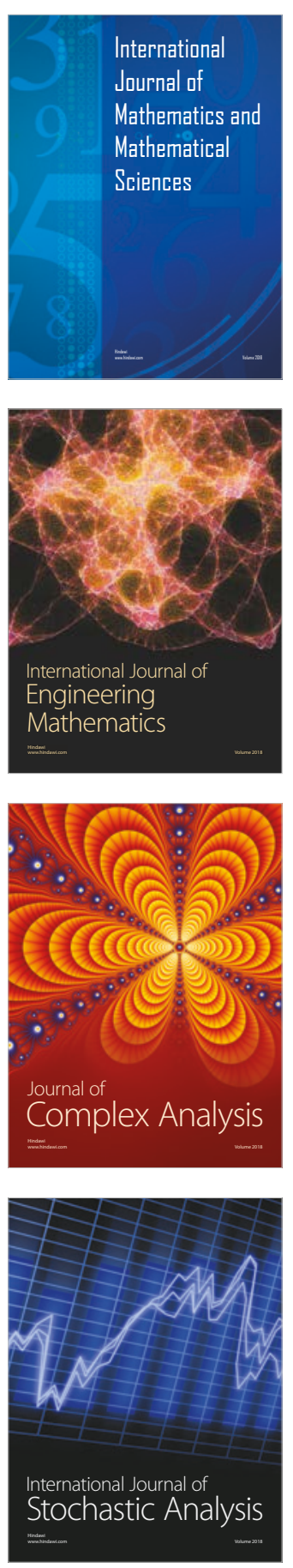
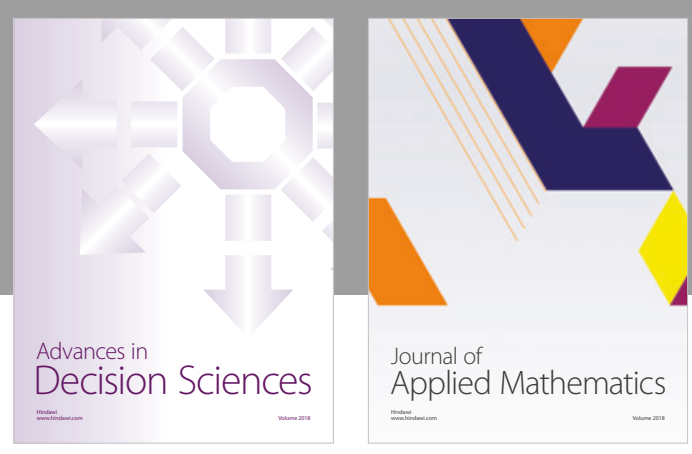

Journal of

Applied Mathematics
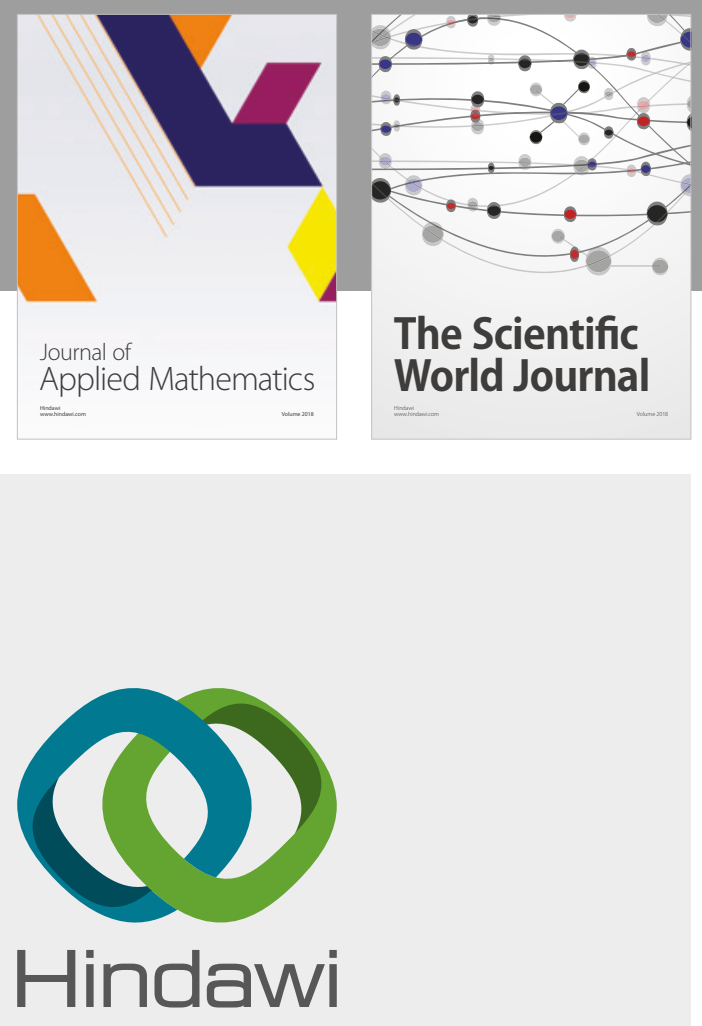

Submit your manuscripts at

www.hindawi.com

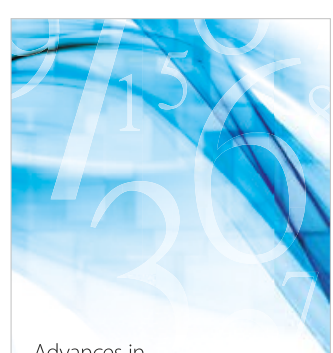

Advances in
Numerical Analysis
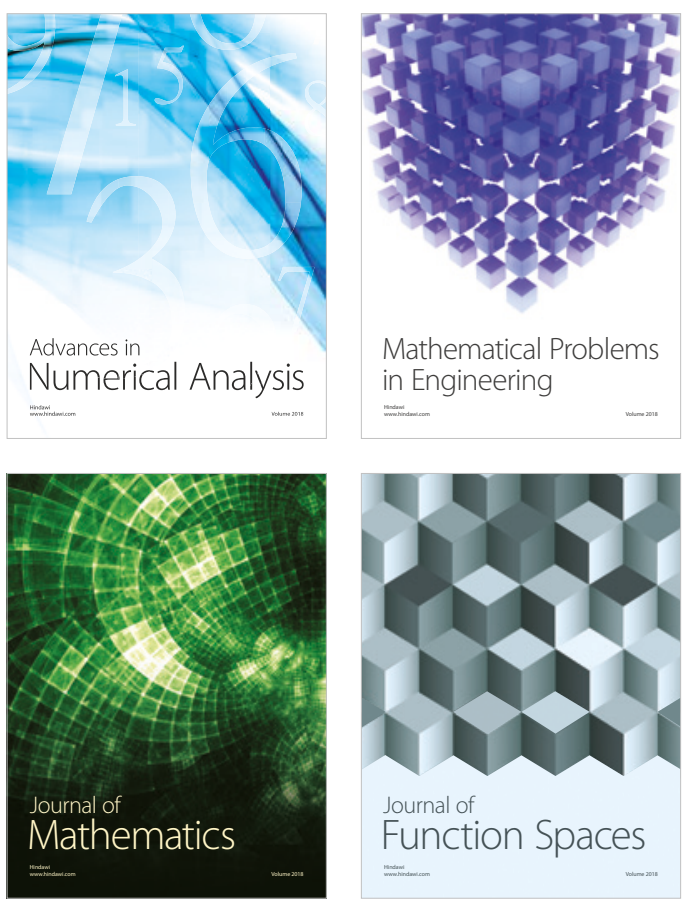

Mathematical Problems in Engineering

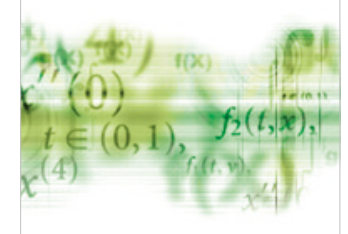

International Journal of

Differential Equations

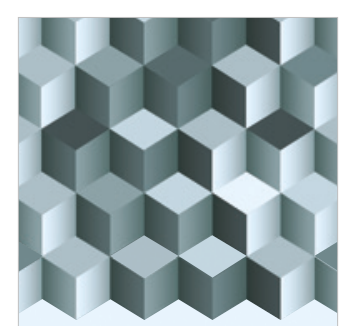

Journal of

Function Spaces
The Scientific

World Journal

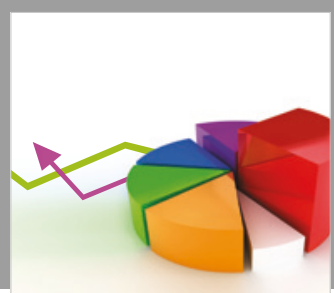

Journal of

Probability and Statistics
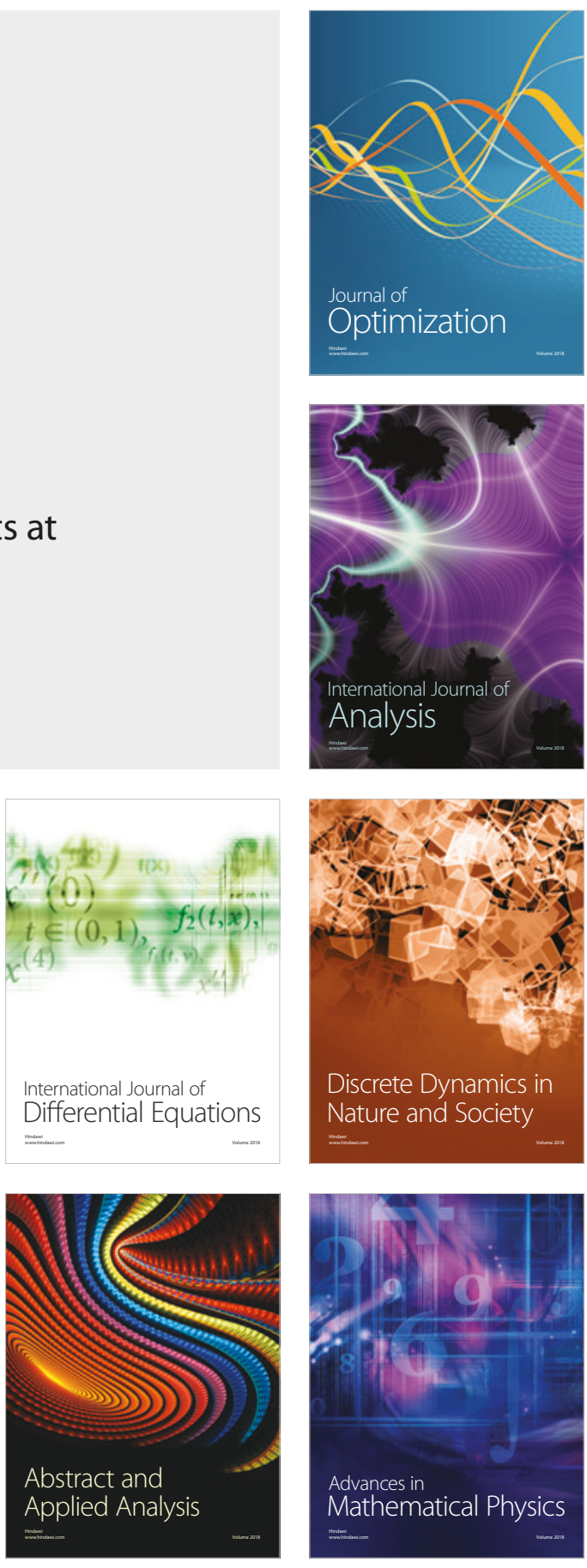